\title{
DEBILITAMIENTO DEL RÉGIMEN POLÍTICO DEMOCRÁTICO Y DE LOS PARTI- DOS POLITICOS
}

\section{WEAKENING OF THE DEMOCRATIC POLITICAL REGIME AND OF THE POLITI- CAL PARTIES}

\section{ENFRAQUECIMENTO DO REGIME POLÍTICO DEMOCRÁTICO E DOS PARTIDOS POLÍTICOS}

Mariela Rubano Lapasta*

RESUMEN. El objeto de este trabajo es examinar el régimen político democrático en la actualidad a la luz de los principios de soberanía nacional y popular, y de participación del ciudadano. Se aborda el rol de los partidos políticos y su importancia, y se argumenta por qué no se puede prescindir de ellos si concebimos la democracia como la mejor forma de gobierno finalizando con algunas conclusiones y propuestas. Se busca que este trabajo sea un aporte en tiempos donde el descontento social, la sensación de desigualdad e injusticia son el síntoma evidente de una población que busca más participación, más incidencia en la res pública, dejando como mensaje que el camino que debemos transitar para avanzar como sociedades es el perfeccionamiento de nuestra democracia.

En efecto, se buscan regímenes que sean más representativos y que aborden las problemáticas desde el Estado de derecho y las vías democráticas.

PALABRAS CLAVES. Participación, democracia, debilitamiento de los partidos políticos.

ABSTRACT. The purpose of this paper is to examine the current democratic political regime taking into account the principles of national and popular sovereignty, as well as citizen participation. The role of political parties and their importance are discussed, and it is argued why they cannot be dispensed with if we conceive democracy as the best form of government, ending with some conclusions and proposals. It is intended that this work be a contribution in times where social discontent, the feeling of inequality and injustice are the obvious symptom of a population in the pursuit of further participation and a broader impact on public matters, leaving as a message that the path we must travel to go

\footnotetext{
* Doctora en Derecho y Ciencias Sociales (U. de la República, Montevideo, Uruguay) Reconocimiento del Título de Abogado por la Corte Suprema de Justicia de Chile. Magister en Derecho Público (Pontificia Universidad Católica de Chile) Profesora de Derecho Político y Derecho Constitucional Universidad San Sebastián-Chile. Correo Electrónico: mariela.rubano@uss.cl; mrubano389@ gmail.com.

${ }^{\circ}$ Maritza Alarcón Cárcamo Ayudante de la cátedra de Derecho Constitucional de la Facultad de Derecho y Gobierno. Universidad San Sebastián. Correo Electrónico malarconc3@correo.uss.cl
} 
forward as societies is the enhancement of our democracy.

In effect, regimes are sought to be more representative and to address issues from the rule of law and the democratic channels.

KEY WORDS. Participation, Democracy, Political parties weakening.

RESUMO. O objetivo deste trabalho é examinar o regime político democrático atualmente, à luz dos princípios da soberania nacional e popular e da participação do cidadão. O papel dos partidos políticos e sua importância são discutidos, e argumenta-se por que eles não podem ser dispensados se concebermos a democracia como a melhor forma de governo, terminando com algumas conclusões e propostas. Pretende-se que este trabalho seja uma contribuição em tempos em que o descontentamento social, o sentimento de desigualdade e injustiça são o sintoma óbvio de uma população que busca mais participação, mais impacto no público, deixando como mensagem que o caminho que devemos percorrer para avançar como sociedades é o aperfeiçoamento de nossa democracia.

Com efeito, buscam-se regimes mais representativos e que abordem questões do estado de direito e dos canais democráticos.

PALAVRAS CHAVES. Participação, democracia, enfraquecimento de partidos políticos.

\section{1.- INTRODUCCIÓN}

El objeto de este trabajo es examinar el régimen político democrático en la actualidad a la luz de los principios de soberanía nacional y popular, y de participación del ciudadano. Se aborda el rol de los partidos políticos y su importancia, y se argumenta por qué no se puede prescindir de ellos si concebimos la democracia como la mejor forma de gobierno, finalizando con algunas conclusiones y propuestas.

De acuerdo a la praxis política, se vive una crisis de representación o quiebre del régimen político, se experimenta un malestar ciudadano, una falta de confianza frente a las instituciones (VALENZUELA, 2011: 24).

Las experiencias democráticas de nuestro tiempo están constituidas -según el parecer de la mayoría- por la apatía del ciudadano indiferente a la política, o como también se dice, despolitizado. Como se desprende de los sondeos de opinión, la mayoría no se interesa por la política, prefiere otra cosa.

Entendemos que algunas formas de enfrentar este problema serían, entre otras, promover una mayor competencia entre los candidatos y ampliar las actuales formas de participación ciudadana.

Se debe alcanzar una mayor cohesión social, en un ambiente de tolerancia y de respeto. Sabemos que la democracia no sólo es un régimen político, sino un estilo de vida que implica un rol protagónico permanente del electorado, qué en tal entendido, debiese convertirse en un contrapeso constante al ejercicio del poder político. 
Lo anterior sin duda ha de incidir en el perfeccionamiento de la democracia política y social, y ha de conducir a una mayor participación libre, informada y responsable de los ciudadanos. Lo indicado, no significa patentar la arbitrariedad, la incertidumbre. Consideramos que el Congreso es el ámbito natural e idóneo para la deliberación en forma pacífica entre gobierno y oposición, siguiendo un procedimiento preestablecido, con posiciones diferentes y generando los consensos necesarios. No se trata entonces de desplazar a la democracia representativa, sino de vigorizarla.

La democracia "en grande" ya no puede ser más que una democracia representativa que separa la titularidad del ejercicio para después vincularla por medio de los mecanismos representativos de la transmisión del poder. El que se añadan algunas instituciones de democracia directa...no obsta para que las nuestras sean democracias indirectas gobernadas por representantes. Se puede responder a esta constatación que "la democracia como es (en la realidad) no es la democracia como debería ser, y que la democracia es, ante todo, un ideal..." (SARTORI, 2010: 346-347).

La democracia no sólo debe ser analizada en el plano del régimen, sino también en el plano del Estado (O'DONELL, 2007: 22). Es un régimen político que refleja aquella: "... forma de gobierno que privilegia la participación de los ciudadanos..." (VIVANCO, 2007: 312).

Se justifica la importancia del tema porque el régimen político democrático se caracteriza por la participación, la movilización, el diálogo entre gobernantes y gobernados, entre el Congreso Nacional y el Ejecutivo, entre mayorías y minorías y entre el Estado y los grupos sociales (CEA EGAÑA, 2015: 201).

El proceso electoral no tiene en la democracia representativa clásica otro objetivo esencial que escoger a las personas que actuarán en nombre de la Nación y darle el título de legitimidad de su autoridad. Una vez elegidos, los representantes no son mandatarios de los electores, sino que interpretan la voluntad nacional. No resulta suficiente el simple reconocimiento del derecho en general "a participar con igualdad de oportunidades", y sobre las bases de igualdad para todos, según las distintas concreciones en los preceptos de la Carta Fundamental. Es además imprescindible la actuación dinámica, creativa, constructiva del Estado para lograr no solo la proclamación, sino, en el hecho, la igualdad de oportunidades abierta a todos, para colocarlos también a todos en el mismo pie de igualdad en la lucha para la obtención de sus objetivos (SILVA, 2010: 77).

2.- EXAMEN DE LOS PRINCIPIOS DE PARTICIPACIÓN POLÍTICA Y LEGITIMIDAD DEMOCRÁTICA

Es sano para toda democracia tener canales de participación ciudadana. En la actualidad, se ha extendido la participación política, por ejemplo, el voto de chilenos en el extranjero (inciso $3^{\circ}$, Artículo 13 de la Constitución Política de la República de Chile):

“...Los ciudadanos con derecho a sufragio que se encuentren fuera del país podrán su- 
fragar desde el extranjero en las elecciones primarias presidenciales, en las elecciones de Presidente de la República y en los plebiscitos nacionales..."

Asimismo, es mayor la participación política de la mujer. En efecto, a partir de la Ley de cuotas, $n^{\circ} 20.840$ de 2015, se impide que algún partido político pueda presentar más del $60 \%$ de candidatos del mismo sexo, asegurando al menos el $40 \%$ de candidatas femeninas, con ello se busca una mayor representación de la mujer en el ámbito político.

La participación ciudadana debe ser coherente entonces con la democracia representativa, que idealmente es concebida como una competencia por la conquista de posiciones de poder en el Estado. El acceso a esas posiciones de poder depende directa o indirectamente de la elección. Los gobernantes son elegidos por los electores o designados por el partido o la coalición que ha ganado las últimas elecciones. Los titulares de esas posiciones disponen oficialmente de una situación estatutaria de decisión y orientación de las "políticas" impulsadas en nombre de las instituciones públicas (GAXIE, 2004: 11).

En consecuencia, el Estado moderno está construido sobre la base esencial de la participación del pueblo en el ejercicio del poder. La democracia constitucional se realiza cuando los destinatarios del poder, organizados como cuerpo electoral, toman parte en el proceso político. Es decir, se debe procurar una amplia participación de la sociedad política y así lograr la legitimidad del régimen político.

La autodeterminación del pueblo o la soberanía popular es la fuente de determinación del poder quien lo delega en autoridades o gobiernos. Esta afirmación es equivalente con la expresión del constituyente “...Ningún sector del pueblo ni individuo alguno puede atribuirse su ejercicio..." (GARCIA, 2016: 271).

La democracia y la ciudadanía son dos conceptos muy vinculados al Estado-Nación: tienen una dimensión liberal, que refiere a los derechos y libertades individuales, y otra social, por ser miembro de una comunidad política (GARRETON, 2005: 8).

El Estado debe aplicar políticas que permitan alcanzar el mayor desarrollo tanto personal y social con igualdad de oportunidades, sin discriminaciones de orden político, económico, social y cultural.

En definitiva, la participación política es un poderoso elemento legitimador del poder político otorgando la correspondiente autoridad. El término consenso es clave para conceptualizar el funcionamiento de la democracia, forma de organización política capaz de gestionar pacíficamente el conflicto social, sólo posible si las dimensiones de éste son limitadas. En efecto, tiene que haber un acuerdo de fondo por la mayoría de la comunidad para permitir la gobernabilidad. La participación política nos puede conducir al consenso, siendo legítimo también el disenso.

En relación a los efectos del principio de participación ciudadana, se señala que el Estado Constitucional se configura a través de una base triangular del poder, ésta es: "representación-participación-democracia" (CUMPLIDO, 2005: 118-119). En efecto, por medio de 
la participación política se articulan los mecanismos de relación entre el sujeto y el objeto del poder político (CUMPLIDO, 2005: 119).

Como ya se dijo, el régimen político democrático se caracteriza por la participación política, económica, social y cultural; también en la movilización, en el diálogo entre gobernantes y gobernados, entre el Congreso Nacional y el Ejecutivo, entre mayorías y minorías y entre el Estado y los grupos sociales.

En conclusión, el término consenso es clave para conceptualizar el funcionamiento de la democracia, forma de organización política capaz de gestionar pacíficamente el conflicto social, sólo posible si las dimensiones de éste son limitadas. En efecto, tiene que haber un acuerdo de fondo por la mayoría de la comunidad. La identidad nacional, el entrenamiento institucional, el régimen existente, la llegada de la oposición al poder no puede significar un cuestionamiento del elemento global de la organización política de la sociedad, todo ello para permitir la gobernabilidad (LIPHART, 1987: 10).

Por lo expuesto, se estima que es un derecho fundamental reconocido a todos los ciudadanos, la participación política, directa o indirecta a través de sus representantes, a los que concurre el pueblo que, debido a la actual impracticabilidad del gobierno directo, se identifica con la idea de representación. Esta significa que el cuerpo social está sometido por la voluntad de la mayoría, por tanto, la participación política nos puede conducir al consenso, siendo legítimo también el disenso. Frente a esta situación cobra importancia la negociación y los acuerdos como instrumentos de un buen gobierno en democracia y una mayor participación del ciudadano, con ello se estaría logrando la legitimidad y la gobernabilidad.

En efecto, la legitimidad es un atributo del Estado que se traduce en la existencia en una parte de la población de un grado de consenso que asegura la obediencia sin que sea necesario recurrir a la fuerza, transformando la obediencia en adhesión (PICAZO, 2016: 60). La democracia constitucional representa el reconocimiento constitucional de los derechos humanos y la concepción de que los titulares o integrantes de los órganos del Estado son elegidos en votación directa. "Todos los que se ven afectados por una decisión deben tener la oportunidad de participar en la toma de decisiones, bien directamente o por medio de representantes elegidos" (LIPHART, 1987: 10).

En ese sentido, se debe concebir el Estado de Derecho como el resultado del proceso de institucionalización jurídica-política de la democracia (DÍAZ, 2002: 75).

El concepto de legitimidad se relaciona con la noción de justicia o de razonabilidad. En efecto, "La legitimidad no considera solamente a las fuerzas políticas, también supone la aceptación de las reglas del juego, son las normas sobre la que opera el régimen". "Un Estado es más o menos legítimo en la medida en que realice el valor de un consenso manifestado libremente por parte de una comunidad de hombres..." (BOBBIO, 1982: 193-195). 
Es decir, "la legitimidad reviste una armonía más profunda que la que proviene meramente de la regularidad técnica de la ordenación positiva y se sitúa en un plano más esencial que toma en cuenta la inspiración y el propósito del mandato público..." (SILVA, 1997: 259).

Como se indica en la Declaración Universidad de Derechos Humanos: "La voluntad del pueblo es la base de la autoridad del poder púbico, esta voluntad se debe expresar mediante elecciones auténticas que habrán de celebrarse periódicamente por sufragio universal e igual y por voto secreto ..." (Artículo 21 inciso $3^{\circ}$ ).

La conservación del poder político se logra, entre otros factores con la participación masiva en el proceso de selección de las autoridades, de ello depende también la conservación del poder (BARROS, 1990: 123).

En síntesis, la participación como elemento esencial de la democracia trae consigo la idea de la incorporación de todos los individuos a la gestación de la voluntad estatal. El ideal del Estado moderno está construido sobre la base esencial de la participación del pueblo en el ejercicio del poder, sin exclusiones de grupos sociales.

La representación se legitima si, además de surgir de un proceso electoral, se apoya en el consenso de los gobernados, al ser aquella intérprete de opiniones, valores, intereses, creencias y necesidades, constituyéndose de este modo no solo en fuente de poder, sino de autoridad.

En la actualidad, cobra significación el rol del ciudadano, de los partidos políticos y los grupos intermedios, como lo señala el autor español Josep Vallés, es necesario vincular el poder con el mundo de las ideas y los valores, es en este mundo donde se encuentran las raíces de la legitimidad de un sistema político determinado y de cada una de las demandas y propuestas que propugnan los diferentes actores. Esta relación "no será siempre la misma y variará según las épocas y sociedades..." (VALLES, 2006: 41).

En síntesis, refuerza la plena vigencia del Estado de derecho y de la democracia el deber del Estado de "...Contribuir a crear las condiciones sociales que permitan a todos y cada uno de los integrantes de la comunidad nacional su mayor realización espiritual y material posible, con pleno respecto a los derechos y garantías que esta Constitución establece..." (inciso $4^{\circ}$, Artículo $1^{\circ}$ Constitución y considerando 13 de la Sentencia del 5 de abril de 1988, Rol n 53 del Tribunal Constitucional).

\section{3.- PARTIDOS POLÍTICOS DEBILITADOS}

Es propio de todo sistema democrático la existencia de partidos políticos. La importancia de estas instituciones radica en su participación en la integración de los órganos de representación y gobierno, y en las funciones de intermediación entre el Estado y la sociedad civil.

En las democracias modernas los partidos políticos se vuelven indispensables porque 
colaboran en los procesos de transición a la democracia y en la profundización y consolidación de la misma.

Desde una concepción amplia se puede sostener entonces que los partidos políticos como agrupación humana han existido desde siempre debido a que "su origen dimana de la propia naturaleza humana, siempre que los hombres en gran número se asocian para la realización de una obra colectiva, se dividen en grupos. "Los partidos constituyen actualmente el instrumento irreemplazable del complejo proceso de la formación de la voluntad política del Estado, el puente entre la masa ciudadana y el poder" (CUMPLIDO, 1998: 17-19), de esta forma se configura el interés por alcanzar el poder del gobierno a través de los partidos políticos, sin descuidar el apoyo ciudadano que es la principal condición y desafío que tienen estas fuerzas políticas para gobernar dentro de un esquema democrático.

Dicho lo anterior es que debemos colocar especial cuidado al trato que damos a los partidos políticos en nuestro ordenamiento jurídico, su importancia en el funcionamiento de algo tan preciado como la democracia nos obliga a contar con reglas claras, además de normas eficientes que permitan un desarrollo mancomunado entre la sociedad civil, los partidos políticos y quienes detentan el poder, orientando todos los esfuerzos en la búsqueda del bien común y de salvaguardar y fortalecer nuestra democracia. Es decir, la base de la democracia no es el consenso, sino el libre disenso, pero hay que destacar que ésos deben estar en niveles razonables (SARTORI, 2000: 47).

Por último, los partidos han transitado históricamente por distintas etapas, luego de su reconocimiento legal, viene una etapa no menos importante, el reconocimiento constitucional (ZOVATTO, 2006: 16-17).

"Si a finales de la década del ochenta el interés por las transformaciones de lo político estuvo asociado a los desafíos de y por la democratización, las transiciones en el Cono Sur y las preocupaciones por el orden político, la incertidumbre en torno al modelo del Estado de Bienestar, el proceso de la Unión Europea y el derrumbe del Muro de Berlín, en los años noventa las transformaciones de lo político generaron la emergencia de intereses distintos y renovados. En efecto, la crisis de los partidos políticos, los límites de la representación y la desafección, el descentramiento de la política y del Estado, existe la percepción creciente de que la democracia se encuentra en retroceso en todo el mundo (LEVITZKY y ZIBLATT, 2020: 237-238).

En este mismo sentido, recordamos algunas ideas relevantes vertidas en el informe emitido por el Consejo Asesor Presidencial contra los Conflictos de Interés, Tráfico de Influencias y Corrupción" En la actualidad los partidos políticos chilenos se encuentran debilitados; los históricos vínculos entre las orgánicas partidarias y la ciudadanía se han venido desgastando. Es así como se ha reducido el porcentaje de la población que integra los partidos mientras la identificación, confianza y valoración de los ciudadanos con éstos y las 
coaliciones han caído a sus niveles más bajos en la historia.... Los factores que explican esta situación son múltiples, algunos vinculados al sistema de incentivos producido por el conjunto de normas y reglas que estructuran el funcionamiento de la democracia: ley de partidos, sistema de registro electoral, sistemas electorales, sistemas de financiamiento de la política e instituciones, y la capacidad para fiscalizar estas normas. Otros factores estarían más asociados a la creciente demanda por mayores niveles de transparencia y democracia interna, en organizaciones que son percibidas por los ciudadanos como distantes y con altos grados de opacidad. (ENGEL, 2015: 66)

En consecuencia, se impone perfeccionar la democracia, que exige numerosos cambios al sistema político vigente, los requerimientos de la ciudadanía son mayores, reclamando más participación, control, transparencia en la actuación de las fuerzas políticas y capacidad decisoria.

Cabe señalar que un sistema democrático es inconcebible sin la existencia de partidos políticos. La importancia de estas instituciones estriba en su participación en la integración de los órganos de representación y gobierno, y en las funciones de intermediación entre el Estado y la sociedad civil. En efecto, son un nexo de la ciudadanía con los poderes estatales, ordenando y canalizando los requerimientos de la sociedad civil con sujeción a doctrinas y programas de bien común.

Por tanto, es fundamental el rol activo de estas fuerzas políticas. Se trata de organizaciones que pasan por una fuerte crisis de credibilidad, de apoyo ciudadano y de debilidades en su funcionamiento, pero no podemos desconocer que son fundamentales en cualquier régimen democrático.

\section{4.- CONCLUSIONES Y PROPUESTAS}

La democracia en cuanto forma de gobierno y en cuanto concepción filosófica, política, constituye un ideal y un objetivo que impone "Un proceso constante de mejoramiento y superación. Debe comprender un espacio político-jurídico, pero además ha de contener de manera imprescindible elementos económicos, sociales y culturales, para poder llegar a constituir la expresión de una verdad vital" (GROS ESPIELL, 2001: 418). Por tanto, resulta necesario vincular el Estado de derecho con la democracia. En efecto, el Estado de derecho es el resultado del proceso de institucionalidad jurídica política de la democracia (DIAZ, 2002: 75).

La plena vigencia del Estado de Derecho y de las instituciones democráticas determina muchos requerimientos en la comunidad política, en la toma de decisiones, como es la exigencia de la participación ciudadana. Ello incide en la estabilidad de las instituciones democráticas y, en definitiva, en la consolidación de una convivencia armónica y pacífica. Un Estado es más o menos legítimo en la medida en que realice el valor de un consenso manifestado libremente por parte de una comunidad de hombres conscientes y autónomos 
(PICAZO, 2016: 60).

Dado el estado actual de desarrollo de la sociedad, el pueblo tendría la posibilidad de ejercer el control permanente de la actuación de sus autoridades por medio de los mecanismos del plebiscito, y de la iniciativa ciudadana de ley, sumado al ya existente de las elecciones periódicas (DELAMAZA, 2010). Concluimos en el insuficiente carácter participativo que esta última tiene, por causa de su origen y de la extrema lentitud y temor para reformarla.

Por tanto, el electorado pasaría así a convertirse en un contrapeso constante al ejercicio del poder político y no actuaría únicamente con la periodicidad con que opera actualmente. Con lo anterior, está claro que la democracia representativa permitiría concretar más plenamente el principio de participación, no sólo como elemento para descomprimir las crisis que se producen, sino para que los ciudadanos tengan un rol directo e indirecto en la construcción y aplicación de las decisiones políticas. Estimamos que ante los cambios y desafíos que plantea la sociedad actual, la democracia debe ser concebida como una construcción permanente, al decir de don José Miguel Insulza. Para ello, el gran desafío es lograr puntos de acuerdo (INSULZA, 2010: 3-4).

Se trata de cuidar la legitimidad de "Futuras inestabilidades e insatisfacciones y ello implica, a la vez que la historia puede de alguna manera volver a comenzar" (FUKUYAMA, 1993: 19-20).

Por lo expuesto, en todo régimen político es de suma relevancia una amplia participación ciudadana, formar en ciudadanía, ello impone un cambio en la relación Estado-Sociedad civil. En efecto, se busca una mejor democracia y mejores instituciones.

En definitiva, estamos asistiendo a un "retorno de la ciudadanía" (Klymlicka and Norman, 1994) en los debates sociales y políticos como en las expresiones ciudadanas, construyendo una "moderna ciudadanía social" (PICAZO, 2016: 317-318).

Es necesario que la sociedad civil ejerza el "control de la agenda", es decir el pueblo decide que temas se someten a la deliberación (ESCOBAR, 2016: 29). La característica de la democracia no es tanto el consenso sino el libre disenso, éste debe estar en niveles controlados a fin de no afectar la gobernabilidad (NOGUEIRA, 2005: 30).

Ante esta situación, cobra significación el rol del ciudadano, de los partidos políticos, las sociedades intermedias y los medios de comunicación, buscando mejorar la calidad de la política y el mantenimiento del Estado Democrático Constitucional de Derecho, consagrado en los artículos 6, 7 y 8 de la Constitución Política de Chile. Un estado de derecho tiene que contar con los medios para garantizar la plena vigencia de los derechos y debe procurar alcanzar el bien común.

Con ello, se podrá alcanzar el consenso político, que resulta imprescindible para el constitucionalismo social y democrático (ZUÑIGA, 2005: 39).

La concreción de la democracia está llena de imperfecciones y limitaciones en relación 
al ideal, y por ello, se dice que la democracia es un régimen político en constante vía de auto-superación y perfeccionamiento, tratando de realizar cada vez más en la realidad la concepción democrática sin nunca lograrlo plenamente (NOGUEIRA, 1986: 17). Por tanto, resulta necesario recurrir a instrumentos de participación del ciudadano. Todo ello con un amplio pluralismo, reconocimiento a la diversidad, iguales derechos, mayor representación y una democracia participativa e inclusiva, transparente y más cercana al electorado.

Un sector de la doctrina sostiene que, la crisis es del Estado moderno, más que de la democracia representativa y del estado de derecho, es del Estado entendido como esfera pública encargada de la defensa de los intereses generales (FERRAJOLI, 2014: 136). En todo Estado de Derecho, las autoridades están sometidas a un sistema de responsabilidades. A ello se agrega el respeto de otros principios, como la credibilidad, la transparencia, la fe pública, el propio régimen democrático constitucional y el respeto y promoción, la naturaleza, el control y los límites del poder político soberano.

Uno de los elementos que afecta la crisis de la democracia representativa, como se indicó precedentemente, es el papel de los partidos políticos, la crisis de representatividad de éstos y los conflictos de intereses. Es relevante abordar el tema, tomando como base los principios contenidos en la Carta Fundamental Democrática Interamericana aprobada por la Asamblea General de la OEA el 11 de septiembre del 2001. En efecto, en este documento se destaca que la democracia representativa se refuerza y profundiza con la participación permanente, ética y responsable de la ciudadanía en un marco de legalidad conforme al ordenamiento constitucional.

Se requieren reformas que permitan mejoras fácticas, y no sólo reformas que aumenten lo frondoso de las legislaciones en los distintos países. Los partidos políticos han sido considerados por las Cartas Magnas de la mayoría de los países. Una reestructuración orgánica a los partidos políticos se vislumbra como la única solución, una reestructuración que vuelva a alinear a la ciudadanía, sus intereses y los partidos políticos.

En efecto, tutelando la confianza en las instituciones políticas, esta confianza permite generar lazos entre los ciudadanos y las instituciones que los representan, siendo un aporte a la legitimidad de los gobiernos democráticos (FUENTES, 2006: 99) y a la consolidación de la democracia.

\section{BIBLIOGRAFÍA}

BARROS, E. (1990). Poder y Derecho en la Democracia Representativa. Santiago de 
Chile: Universidad Católica.

BOBBIO, N.; MATTEUCI EN RUZ, N; PASQUINO, G. (1982). Diccionario de Ciencias Políticas. Concepción Chile: Editorial Universidad de Concepción.

CEA EGAÑA, J. (2015). Derecho Constitucional Chileno. Santiago de Chile: Universidad Católica.

CUMPlido, F. NOGUEIRA, H. (1998). Las Fuerzas Políticas. Santiago de Chile: Editorial Jurídica Ediar Conosur Ltda.

CUMPLIDO CERECEDA, F. (2005). Reforma Constitucional y Régimen Político en Reforma Constitucional. Santiago de Chile: Editorial Lexis Nexis.

DELAMAZA, G. (2010). La disputa por la participación en la democracia elitista chilena. Latin American Research Review, 45, 274-297. Recuperado de www.jstor.org/stable/27919222

DÍAS, E. (2002). Estado de Derecho, y Legitimidad Democrática. Madrid: Alianza Editorial.

ESCOBAR BERGUES, D. (2016). Democracia Constitucional. Revista Jurídica Universidad Católica Nuestra Señora de la Asunción.

FERRAJOLI, L. (2014). La Democracia a través de los Derechos. El Constitucionalismo garantista como modelo teórico y como proyecto político. Madrid: Editorial Trotta.

FUENTES, C. et al. (2006). Desafíos democráticos, Santiago de Chile: Editorial LOM. FUKUYAMA, F. (1993). El Futuro Después del Fin de la Historia. Estudios Públicos. GARCÍA PINO, G. et all. (2016) Diccionario Constitucional Chileno. Santiago de Chile: Editorial Hueders.

GARRETÓN, M. (2005). Inscripción automática y obligatoriedad del voto. Revista Tiempo 2mil. (84), 1-16. Recuperado de http://www.manuelantoniogarreton.cl/documentos/Voto\%20Obligatorio.pdf

GAXIE, D. (2004). La Democracia Representativa. Santiago de Chile: LOM Ediciones. GROS ESPIELL, H. (2001). La Democracia en el Sistema Interamericano en Temas Internacionales. Montevideo: Melibea Ediciones.

INSULZA, J. (2010). La Democracia como Construcción Permanente. Revista de Ciencia Política, 30 (1), 3-4. http://dx.doi.org/10.4067/S0718-090X2010000100001

LEVITSKY, S. ZIBLATT, D. (2020). Cómo mueren las Democracias. Santiago: Editorial Planeta Chilena S.A.

LIJPHART (1987). Las Democracias Contemporáneas. Un estudio comparativo. Barcelona: Editorial Ariel.

Nogueira Alcalá, Humberto. (1986). Teoría y Práctica Democrática. Santiago de Chile: Editorial Andante.

NOGUEIRA ALCALÁ, H. (2005). El rol de los partidos políticos en las Constituciones de América Latina en la alborada del siglo XXI. Estudios Constitucionales. Año 3 (2), 
309-360.

O’DONELL, G. (2007). Disonancias. Críticas democráticas a la Democracia. Buenos Aires: Prometeo Libros.

PICAZO, I.; MONTERO, V. y JEANNE, S. (2016). Diccionario de Ciencia Política. Concepción Chile: Editorial Universidad de Concepción.

SARTORI, Giovanni. (2000). Partidos y Sistemas de Partidos. Madrid: Editorial Alianza. SARTORI, Giovanni. (2010). Elementos de Teoría Política. Madrid: Alianza Editorial. SILVA BASCUÑÁN, Alejandro. (1997). Tratado de Derecho Constitucional. Santiago de Chile: Editorial Jurídica de Chile.

SILVA BASCUÑÁN, Alejandro. (2010). Tratado de Derecho Constitucional. Santiago de Chile: Editorial Jurídica de Chile.

SQUELLA NARDUCCI, A. (2011). ¿Qué Democracia? Diario El Mercurio.

VALENZUELA, A. (2011). Crisis de Representación y Reforma Política en Chile. Centro de Estudios Públicos: CEP y Corporación de Estudios para Latinoamérica: CIEPLAN. VALLÉS JOSEP, M. (2006). Ciencia Política. Una Introducción. Barcelona: Editorial Ariel.

VIVANCO MARTÍNEZ, Á. (2007). Curso de Derecho Constitucional. Santiago de Chile: Ediciones Universidad Católica de Chile.

ZOVATTO, D. (2006). Regulación de los partidos políticos en América Latina, Diálogo Político. Publicación trimestral de la Fundación Konrad-Adenauer-Stiftung A.C. ZÚÑIGA URBINA, F. (2005). Democracia y Estado de Derecho. Santiago de Chile.

Jurisprudencia.

Edito Sentencia Tribunal Constitucional Rol N567-2010. 